УдК 332.1

МЮБАВИНА СВЕТААНА ВЯЧЕСААВОВНА

заместитель директора Астраханского филиала АО СОГАЗ, e-mail: lubavina_sveta@mail.ru

\title{
ОПТИМИЗАЦИЯ ИНФОРМАЦИОННОЙ СИСТЕМЫ ПРОЦЕССА УПРАВАЕНИЯ РЕГИОНОМ
}

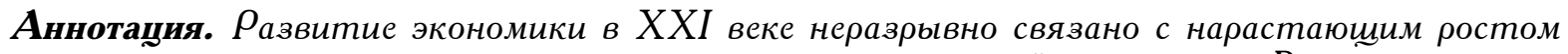
влияния информатизации всех социальных сфер и отраслей экономики. В период интенсивного развития информационной среды регионы пользуют информациионные технологии в иуелях повышения эффективности реализациии стратегии социально-экономического развития. Необходимость исследования состояния региональных информационных систем и разработка алгоритма оптимизаиии определили актуальность данного исследования. В качестве объекта исследования в статье выступают отрасли экономики Астраханской области. Предмет исследования - действующлие методические подходы информатизайии и формирования информационных систем на региональном уровне. В качестве основных методов исследования использовался сравнительный анализ, системный анализ, применялись сочетания количественных и качественных подходов. Результаты: 1. Разработан алгоритм оптимизации информационной системы управления регионом 2. Проведен кластерный анализ отраслей региона по уровню информатизации (на примере Астраханской области). Область прнменения. Полученные в ходе исследования результаты следует использовать для анализа уровня информатизации регионов и, возможно, применять в рамках любых региональных отраслей и органов управления, использующих проектные методы регионального развития. Выводы. Совершенствование проиессов управления регионом невозможно без эффективной региональной информационной системы. Следовательно, возникает необходимость совершенствования методических подходов исследования информатизации регионов, оценки факторов и условий развития информационной системь для формирования направлений оптимизации и реоганизации в цूелях повышения эффективности управления регионом.

Ключевые слова: региональная информационная система, кластерный анализ отраслей региона, управление регионом.
\end{abstract}

\section{LYUBAVINA SVETLANA VYACHESLAVOVNA Associate Director of the Astrakhan branch of JSC SOGAZ,} e-mail: lubavina_sveta@mail.ru

\section{OPTIMIZING THE INFORMATION SYSTEM OF REGIONAL PROCESS MANAGEMENT}

Abstract. The development of the economy in the 21st century is inseparably connected with the growing influence of the informational support of all social spheres and industries of the economy. During the period of intensive development of the information environment, the regions of the Russian Federation are more actively using information technologies in order to increase the effectiveness of implementation of the strategy of the social-economic development. The need to study the state of the regional information systems and develo $\rho$ an algorithm of optimization determined the relevancy of this study. The object of the study in this manuscript are economic industries of the Astrakhan Region. The subject of the study are active methodical approaches of informational support and forming information systems on the regional level. The main methods of the study were comparative analysis, systemic analysis, the use of a combination of qualitative and quantitative approaches. The results: 1 . We have developed an algorithm of optimization of the information system of regional management 2. We have completed a cluster analysis of the industries of the region based on the informational support level (on an example of the Astrakhan Region). The area of application. The results obtained in the course of the study 
should be used to analyze the level of informational support of regions and can be used within the context of any regional industry and administrative authorities using project-oriented methods of regional development. The conclusions. Improving management processes of the region is impossible without having an effective regional information system. Therefore, there is a need to improve the methodical approaches of studying the informational support of regions, evaluation of factors and conditions of development of the information system, to form areas of focus of optimization and reorganization in order to improve the effectiveness of regional management.

Keywords: the regional information system, a cluster analysis of regional industries, regional administration.

\section{Введение}

Современный этап экономики характеризуется развитием систем управления, в которых информационные технологии являются базовым фактором роста качества управления как производственного, так и муниципального и государственного уровней. Динамика этих процессов находит свое отражение в реорганизации регионального управления, через создание информационно-аналитических структур. Достоверный и актуальный мониторинг социальноэкономического развития региона является главной целью информационной системы, так как качественные характеристики входящей информации напрямую определяют качественный уровень процесса управления регионом [2]. Здесь мы акцентируем внимание на модернизации всего спектра социально-экономической информации, в том числе статистической, банковской и другой, обуславливающей решение комплекса задач регионального уровня.

Классификация и анализ существующих информационных систем регионального управления.

В условиях экономики советского периода информационная система, как и все процессы управления, имела вертикальный порядок. Весь объем информационных ресурсов, задействованный в управлении экономическими процессами, проходил через многоступенчатые системы министерств, Госплана и Госснаба [16].

Современная экономика характеризуется иной ролью региональных экономических систем. Значительно возросли возможности и компетенции региональных органов власти, как следствие возник спрос на информационный ресурс в разрезе регионального применения, что привело к созданию региональных информационных систем. Существующие различные подходы к классификации региональных информационных систем мы объединим в три класса [4, $5,6,15]$ :

Информационные системы первого класса характеризуются развитой региональной инфраструктурой и применением широкого спектра информационных технологий, что позволяет им достаточно полно закрывать существующие региональные информационные потребности.

В состав информационных систем второго класса мы включаем региональные системы с развитой инфраструктурой и отстающей системой региональных коммуникаций.

К информационным системам третьего класса мы относим информационные системы региональных органов управления, созданные для решения внутренних задач и не входящие в единую систему управления регионом.

Согласно законодательству РФ по виду собственности, информационные ресурсы могут быть частными и государственными [7]. Консолидация и обработка социально-экономической информации традиционно осуществляется органами статистики и профильными региональными ведомствами. Определяющее влияние информационный ресурс оказывает на развитие информационных систем. Интеграция информационных ресурсов является базовым фактором эффективности управления экономикой региона.

В данном исследовании мы рассмотрим систему оценки информационных ресурсов и механизм оптимизации региональной информационной системы. На заключительном этапе сделаем выводы об эффективности будущей и существующей региональной информационной системы.

Методические подходы к оптимизации информационной системы процесса управления регионом.

Результаты анализа развития региональных информационных систем показали, что эффек- 
тивность управления регионом напрямую зависит от качества управленческой информации. Поскольку база получаемого информационного ресурса основывается на мониторинге социально- экономических показателей, то эта функция является неотьемлемым элементом деятельности региональных информационных служб. В настоящее время повышаются требования к качеству информационных технологий, используемых в управлении регионом [10]. Управленческие подразделения территориальных органов сталкиваются, с одной стороны, с проблемой недостаточности необходимой информации, а с другой стороны - с переизбытком информации получаемой для дальнейшего анализа. Поэтому важнейшей задачей эффективного управления становится оптимизация информационной системы в разрезе характеристик информационных ресурсов и особенностей развития региона.

Ступенями предлагаемого алгоритма являются следующие этапы:

1. Анализ существующих отраслевых и региональных информационных ресурсов.

2. Исследование трафика движения информационных ресурсов.

3. Кластерный анализ отраслей региона по уровню информатизации (на примере Астраханской области).

4. Разработка региональных регламентов обработки информации.

5. Разработка и внедрение информационной системы управления региона.

6. Составление программы развития информационной системы процесса управления региона.

Исходя из вышесказанного, эффективность и результативность регионального управления зависит от ряда количественных и качественных критериев информационной системы, а также от планируемых результатов, которые мы можем отразить в алгоритме оптимизации в разрезе используемой информационной технологии на рисунке 1.

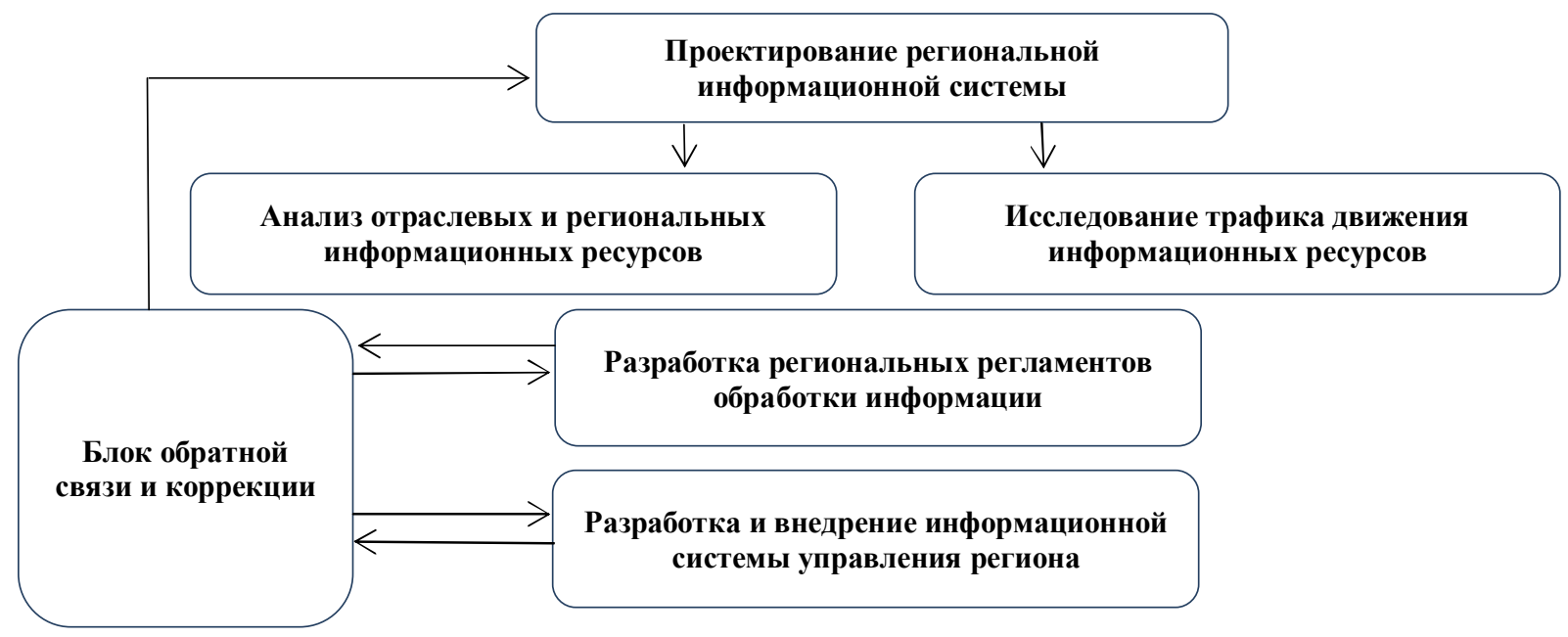

Рис. 1. Алгоритм оптимизации информационной системы управления региона.

Этап 1. На данном этапе исследуется документооборот, определяются критерии получаемой информации с учетом мнений специалистов и экспертов как потребителей информации. На этом же этапе задается процедура анкетирования и процедура оценивания, задающая сравнительные параметрические характеристики. Основным методическим подходом этого этапа является определение направления исследования, так как потребители зачастую не владеют данными о потенциале сложившихся информационных систем. Процесс сбора, обработки и структурирования информации можно представить в виде следующих стадий:

- получение и классификация информации для ее структурирования и распределения между получателями;

- видоизменение и подготовка информации в соответствии с требованиями получателей информации.

Исследование информационных баз на этом этапе основывается на использовании следующих информационных характеристик в разрезе вида исходной информации, канала движения информации и шкалы весовой оценки в таблице 1. 
Оценка весовых характеристик информационной системы подразделений региональных органов

\begin{tabular}{|c|l|c|c|}
\hline \multicolumn{2}{|c|}{ Характеристика информации } & Информационный ресурс & Канал движения \\
\hline № & Описание характеристики & $\mathbf{0 - 1 0}$ & $\mathbf{0 - 1 0}$ \\
\hline 1 & Оперативность & & $\mathrm{x}$ \\
\hline 2 & Количество & $\mathrm{x}$ & $\mathrm{x}$ \\
\hline 3 & Доступность & $\mathrm{x}$ & $\mathrm{x}$ \\
\hline 4 & Актуальность & $\mathrm{x}$ & $\mathrm{x}$ \\
\hline 5 & Объем & $\mathrm{x}$ & $\mathrm{x}$ \\
\hline 6 & Применимость & $\mathrm{x}$ & $\mathrm{x}$ \\
\hline 7 & Ценность & & \\
\hline 8 & Достоверность & & \\
\hline
\end{tabular}

Экспертная оценка позволяет охарактеризовать разнородность информационных ресурсов, определить потребности и требования к информации.

Этап 2. Важным этапом процесса управления региональной экономикой является исследование трафика движения информационных ресурсов. Данное исследование необходимо для формирования системности управления социально-экономическим развитием региона. Трафик информации движется не только по вертикали, но и по горизонтали: между структурными подразделениями, между районами и ведомствами. Здесь мы осознанно применили определение «движение», так как на этом этапе мы исследуем не характеристику информационного ресурса, а процесс движения информации. Трафик движения информации характеризуется двумя факторами: сложностью информации и уровнем развития информационной системы.

\begin{tabular}{|c|c|c|c|c|}
\hline Вход информации & $\longrightarrow$ & Обработка & $\rightarrow$ & Передача \\
\hline Поиск & \multirow[t]{2}{*}{$<$} & Хранение & \multirow[t]{2}{*}{$<$} & Анализ \\
\hline Принятие решений & & Контроль исполнения & & Выход информации \\
\hline
\end{tabular}

Рис. 2. Схема трафика движения информационных ресурсов.

Представленная схема описывает движение информационных ресурсов от входа (источника) информации до выхода (потребителя) информации. В процессе движения каждый этап трафика имеет качественную характеристику Q, отражающую не только скорость движения информации, но и соответствующий процесс преобразования информации. Если $\mathrm{Q}$ - каче-

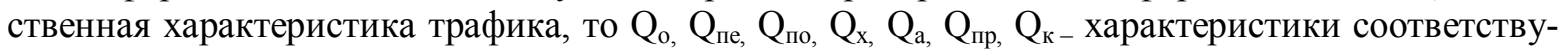
ющих звеньев схемы, тогда:

$\mathrm{Q}=\left(\mathrm{Q}_{\mathrm{o}}, \mathrm{Q}_{\text {пе, }}, \mathrm{Q}_{\text {по, }}, \mathrm{Q}_{\mathrm{x}}, \mathrm{Q}_{\mathrm{a}}, \mathrm{Q}_{\text {пр, }}, \mathrm{Q}_{\mathrm{k}}\right)$;

$\mathrm{Q}$ - это интегральный показатель трафика движения информационных ресурсов. На основе анализа и синтеза полученных расчетных данных мы обобщим информацию о характеристиках региональной информационной системы, ее слабых местах и точек роста эффективности.

В качестве прикладного инструментария оценки уровня развития информационной системы региона мы предлагаем:

Этап 3. Кластерный анализ отраслей региона по уровню информатизации (на примере Астраханской области).

Информационные базы данных отраслей региона представляют собой информационный комплекс, состоящий из необходимых для управления данных, систематизированных определенным образом в целях повышения качества производственных процессов. Система мониторинга информации используется для повышения эффективности процессов управления, вы- 
полняя функцию выявления изменений внешней среды, оказывающих влияние на экономическую систему региона.

В настоящее время субъекты экономической системы региона не могут функционировать вне региональной информационной системы. Без трансформации информационных технологий в соответствии с современными реалиями невозможно осуществлять на основе них эффективное управление. Исходя из современных тенденций в управлении региональной экономикой, мы обозначим следующие критерии развития отраслевых информационных систем:

$\mathrm{X}_{1-}$ затраты на информатизацию учреждения, предприятия в рублях;

$\mathrm{X}_{2}$ удельный вес автоматизированных рабочих мест к общему количеству рабочих мест;

$\mathrm{X}_{3}$ - удельный вес автоматизированных рабочих мест с доступом к сети Internet;

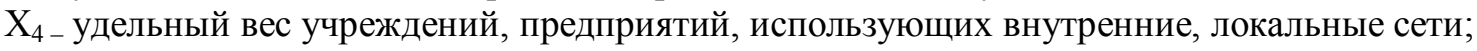

$\mathrm{X}_{5}$ - удельный вес учреждений, предприятий, использующих внешние, глобальные сети;

$\mathrm{X}_{6}$ - удельный вес учреждений, предприятий, имеющих собственные веб-ресурсы;

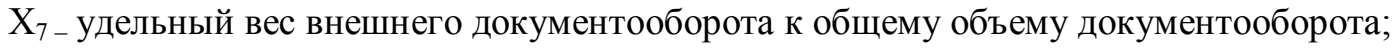

$\mathrm{X}_{8-}$ удельный вес внутреннего электронного документооборота к общему объему документооборота;

$\mathrm{X}_{9}$ - удельный вес внешнего электронного документооборота в объеме внешнего документооборота.

Исходя из этих критериев, производится расчет интегрального показателя информатизации отраслей региона. Интегральный показатель информатизации отраслей региона отражает уровень региональной информационной системы. Полученные итоговые значения сопоставляются с индикативными значениями развития региональной информационной системы.

Для исследования кластеризации региональных отраслей необходимо выделение количества отраслей, наиболее полно отражающих социально-экономическое развитие региона. Для экономики Астраханской области мы выделили 11 отраслей: теплоэнергетическая отрасль, государственное управление и налоговые органы, кредитно-финансовая отрасль, добыча нефтеуглеводородов, отрасль связи, судостроение, здравоохранение, образование, транспорт, сельское хозяйство, розничная торговля [25]. Далее мы ранжировали отрасли по критериям развития отраслевых информационных систем. В результате ранжирования мы распределили отрасли Астраханской области по четырем кластерам (таблица 2).

В первый кластер входит теплоэнергетическая отрасль. Первый кластер характеризуется наивысшим уровнем информатизации внутренней информационной системы и средним уровнем доступности внешним пользователям.

Таблица 2

Кластеризация отраслей экономики Астраханской области по уровню информатизации

\begin{tabular}{|c|c|c|}
\hline № Кластера & Количество отраслей & Состав кластера \\
\hline I & 1 & Теплоэнергетическая отрасль \\
\hline II & 2 & $\begin{array}{c}\text { Государственное управление и налоговые органы; } \\
\text { кредитно-финансовая отрасль }\end{array}$ \\
\hline III & 3 & $\begin{array}{c}\text { Добыча нефтеуглеводородов; } \\
\text { розничная торговля; } \\
\text { отрасль связи; }\end{array}$ \\
\hline IV & 4 & $\begin{array}{c}\text { 3дравоохранение; } \\
\text { образование; } \\
\text { судостроение; } \\
\text { транспорт. }\end{array}$ \\
\hline
\end{tabular}

Во второй кластер входят: налоговые и государственные органы, а также кредитнофинансовые учреждения. Второй кластер характеризуется высоким уровнем информатизации внутренней информационной системы и высоким уровнем доступности внешним пользователям. 
В третий кластер входят: отрасль добычи нефтеуглеводородов, розничная торговля и отрасль связи. Третий кластер характеризуется высокими относительными показателями, такими как: динамика информатизации организаций отрасли, динамика роста вложений на информатизацию организаций отрасли.

В четвертый кластер входят отрасли социальной сферы (здравоохранение и образование), а также судостроение и транспортная отрасль. Общими характеристиками этого кластера является высокий уровень автоматизации рабочих мест, но в то же время самые низкие затраты на автоматизацию в расчете на одного работника. Также все организации этих отраслей имеют собственные веб-ресурсы и используют внешние информационные сети.

На основе методов кластерного анализа мы классифицировали однородные группы региональных отраслей, сгруппированных в разрезе видов деятельности и ранжированных по уровню развития отраслевой информационной системы. Исследовали влияние критериев развития информационных систем на развитие социально и экономически значимых отраслей региональной экономики. Данное исследование позволило рассчитать цифровое значение интегрального развития информационной системы отраслей для каждого кластера. Анализируя результаты кластеризации, мы сформулировали предложения, реализация и внедрение которых будет способствовать выравниванию уровня развития информационных систем отраслей, а также повысит уровень региональной информационной системы.

Этап 4. Разработка региональных регламентов обработки информации.

По результатам первых трех этапов разрабатываются общие требования к регламентам и информационным базам и комплексам. Систематизация информации, оказывающая влияние на процесс управления, выражается через информационный комплекс, который представляет собой классификацию следующих видов информации:

- по периодичности предоставления информации: оперативная, ежеквартальная, годовая, постоянная, переменная;

- по видам экономического анализа: плановая, учетная, внеучетная;

- по степени проверенности: объективная, субъективная, достоверная, недостоверная;

- по источнику возникновения: первичная, вторичная;

- по отношению к экономическому субъекту: входящая, исходящая, обрабатываемая, необрабатываемая;

- по типу визуализации: текстовая, графическая.

Исходя из этого, процесс принятия управленческих решений напрямую увязывается с процессом обработки информации и состоит из следующих 4 стадий (рисунок 3 ).

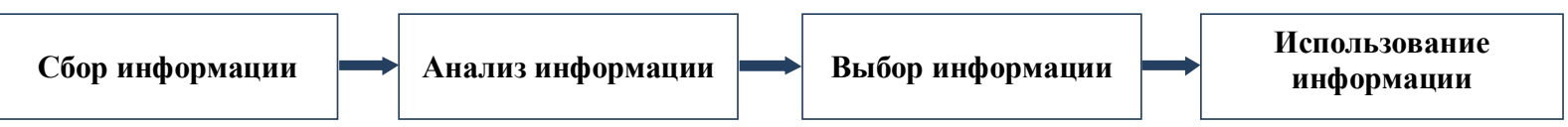

Pис. 3. Стадии обработки информачии.

Определяются субъекты-участники процесса обработки информации: структурные подразделения и органы исполнительной власти. Определяется порядок обработки поступающего из внешней среды информационного ресурса. Определяется контрольный орган, отвечающий за функционирование «Блока обратной связи и коррекции», согласно алгоритму оптимизации информационной системы управления региона. В сферу деятельности также входит анализ результатов обработки информации и составление аналитических докладов. Ответственность за исполнение тех или иных регламентов и ведение информационных баз распределяется по совокупности критериев: уровень актуализации данных, уровень аналитических наработок, уровень технической оснащенности.

Этап 5. Разработка и внедрение информационной системы управления региона.

Внедряя информационную систему в регионе, необходимо учитывать два основных фактора. Первый - необходимость реорганизации структуры управления регионом в разрезе оптимизирования внутренних взаимосвязей структурных подразделений. Вторая - оптимизация существующих элементов информационной системы в разрезе внедрения технологий, отвечающих современным требованиям [1]. Исходя из сложившихся глобальных тенденций в управ- 
лении экономическими системами, применяются такие современные информационные технологии, как:

- первичные интернет-технологии (интернет-сайт, электронная почта и другие);

- технологии информационных хранилищ и клиент-серверов;

- технологии создания и конструирования информационных баз данных и систем;

- географическая информационная система;

- мультимедийные технологии как комплекс информационных систем, обладающих уникальными специфическими формами и назначением;

- информационные системы, разработанные для автоматизации стратегий региона путем создания и усовершенствования процессов управления и процессов мониторинга и коррекции.

Указанные выше технологии позволяют создавать проблемно актуированные, удаленно доступные региональные информационные системы как необходимые приложения эффективного управления регионом.

Создавая региональную информационную систему, следует учесть возможность сквозной технологии сбора, обработки и структурирования информации с учетом требований экономической безопасности и защищенности информационных ресурсов, в зависимости от уровня доступа.

Прикладным инструментарием этого этапа будет дорожная карта внедрения информационной системы. В дорожной карте будут присутствовать как поставщики информационных ресурсов для региональных органов управления, так и весь спектр существующих и планируемых пользователей системы. В дорожной карте производится группировка взаимосвязей блоков информационных ресурсов по группам пользователей информационной системы. Фактически дорожная карта является техническим заданием сетизации органов и процессов управления регионом.

Современное развитие информационных систем создало предпосылки развития двух направлений информационных технологий, оказывающих определяющее воздействие на процессы управления регионом:

1. Технологии удаленного управления и доступа на территориально распределенных местах осуществляемой деятельности, что приводит к существенной экономии на издержках коммуникации, перемещения и оперативности.

2. Технология информационного посредника, получившая официальный статус в российской информационной системе. Данная технология снижает информационную нагрузку, повышает эффективность таких управленческих функций, как коммуникации, скорость организационных процедур и другие.

Трансформация информационной системы влечет за собой и изменения структуры управления регионом. Изменения структуры управления выражается в изменении количества структурных подразделений, перераспределении выполняемых ими функций, качественных и количественных взаимосвязей внутри структуры. Итогом этих изменений является улучшение показателей эффективности управления регионом.

Эффективностью управления регионом мы считаем достижение планируемых социальноэкономических показателей при реализации выбранной стратегии развития. К результатам эффективности мы можем отнести:

- скорость и объем собранной информации о состоянии региональной экономики;

- скорость и объем получения информации исполнителями;

- эффективность системы регионального мониторинга;

- сокращение традиционных издержек на осуществление процессов управления;

- сокращение временных издержек на осуществление процессов управления регионом.

Этап 6. Составление программы развития информационной системы процесса управления региона.

Итоговым документом, обобщающим результаты предыдущих этапов, будет являться программа развития информационной системы управления региона. Можно сформулировать принципы и цели этой программы.

Основные принципы оптимизации информационной системы региона:

- расширение числа пользователей информационной системы и использования современ- 
ных информационных технологий;

- создание комплекса защиты информационной системы в разрезе использования конфиденциальных данных;

- мониторинг данных и контроль доступа в разрезе единства и совмещения размещаемой информации.

Основными целями программы развития информационной системы управления региона являются:

- формирование единой региональной информационной системы для повышения эффективности процессов управления в регионе;

- создание региональных накопительных баз и банков данных;

- развитие информационно-аналитической среды, обеспечивающей региональные структуры и ведомства данными, для управления и принятия решений.

\section{Заключение}

Проведенный анализ аспектов оптимизации информационной системы управления регионом позволяет констатировать следующее:

- отрасли региональной экономики имеют существенный дисбаланс развития по уровню информатизации;

- процессы управления регионом нуждаются в эффективной информационной системе;

- предложенный алгоритм оптимизации повысит качество информационной среды, и как следствие - уровень управления регионом.

Расширение использования информационных технологий и оптимизация региональных информационных систем послужит катализатором роста позитивного влияния на процессы социально-экономического развития регионов Российской Федерации.

Лuтература

1. Анфилатов В. С., Емельянов А. А., Кукушкин А. А Системный анализ в управлении / под ред. А. А. Емельянова. М.: Финансы и статистика. - 2005.

2. Афоничкин А. И., Михайленко Д. Г. Управленческие решения в экономических системах: учебник для вузов. - СПб.: Питер, 2009.

3. Берка, Карел. Измерения. Понятия, теории, проблемы / Mereni. Pojmy, teorie, problemy: nер. с чеш. М.: Прогресс, 1987.

4. Бугорский В. Н., Соколов Р. В. Экономика и проектирование информационных систем. СПб.: РИФ «Роза мира», 1998.

5. Варфоломеев В. И., Назаров С. В. Алгоритмическое моделирование элементов экономических систем. М.: Финансы и статистика, 2004.

6. Информационные системы и технологии в экономике: учебник, 2-е изд., доп. и перераб. / под ред. В.И. Лойко. М.: Финансы и статистика, 2003.

7. Коломиеи В. Ф. Международные информационные системы: Учебник / под ред. проф. В.П. Гондюл. М.: иентр «Киевский университет», 2001.

8. Литвак Дж., Лавров А., Сазерлэнд Д. Реформа межбюджетных отношений в России: федерализм созданный рынком // Вопросы экономики, 2001. - № 4.

9. Любавина С. В. Управление экономическими системами: монография / авторский коллектив под общ. ред. Б.Н. Герасимова. - Выпуск 11. - Пенза; Самара; Краснодар: Приволжский Дом знаний; СНИУ; КубГТУ, 2017.

10. Минакир П. Трансформация региональной экономической политики // Проблемь теории и практики управления, 2001. - № 2 .

11. Норт Д. Институты, институииональные изменения и функиионирование экономики. - М.: Фонд экономической книги «Начала», 1997.

12. Петросяни В. З., Дохолян С. В., Петросяни Д. В., Баширова А. А. Стратегия регионального развития в условиях инновационных преобразований экономики. - М.: Экономика, 2011.

13. Планкет Л., Хейл Г. Выработка и принятие управленческих решений. - М.: Мир, 1984.

14. Поппель Г., Голдстайн Б. Информационная технология - миллионные прибыли. - М.: Экономика, 1990.

15. Проектирование экономических информационных систем: учебник / Г. Н. Смирнова, А. А. Сорокин, Ю. Ф. Тельнов. М.: Финансы и статистика, 2005.

16. Региональная экономика и управление: учеб. пособие, 2-е изд., перераб. и доп. - СПб.: Питер, 2008.

17. Саймон Г. Теория принятия решений в экономической теории и науке о поведении: $B$ кн.: «Теория фирмы»».-СПб., 1995.

18. Стрелеи И. А. Новая экономика и информационные технологии. М.: Экзамен, 2003.

19. Теория систем и системный анализ в управлении организаичями: учеб. пособие / под ред. В.Н. Волковой. М.: Финансы и статистика, 2006. 
20. Шенк Р. Обработка кониептуальной информации: Пер. с англ. - М.: Энергия, 1980.

21. Эддоус М., Стенсфилд Р. Методы принятия решений / Пер с англ. под ред. Н.И. Елисеевой. - М.: Банки и биржи, 2001.

22. Castells M. The Information Age: Economy, Society and Culture: The Rise of the Network Society. Maiden (Ma.). Oxford: Blackwell Publ., 1996.

23. Stigler $G$. The Economics of information, 1961.

24. Ross A. Industries of the future. AST Publishers, 2017.

25. [An electronic resource]. Access mode: https://minec.astrobl.ru/document/strategia-socialnoekonomiceskogo-razvitia-astrahanskoi-oblasti-do-2020-goda, free. Heading from the screen.

\section{References:}

1. Anfilatov V. S., Emelyanov A. A., Kukushkin A. A Sistemnyj analiz v upravlenii [System analysis in management]. M.: Finance and statistics, 2005.

2. Afonichkin A. I., Mihajlenko D. G. Upravlencheskie resheniya v ehkonomicheskih sistemah: uchebnik dlya vuzov [Management decisions in economic systems: textbook for universities]. SPb.: Peter, 2009.

3. Berka, Karel. Mereni. Pojmy, teorie, problemy [Measurements. Concepts, theories, problems ]. M: Progress, 1987.

4. Bugorski V. N., Sokolov R. V. Ekonomika i proektirovanie informacionnyh system [The Economy and design of information systems]. SPb.: "Rose of the world», 1998.

5. Varfolomeev V. I., Nazarov S. V. Algoritmicheskoe modelirovanie ehlementov ehkonomicheskih system [Algorithmic modeling of elements of economic systems]. M: Finance and statistics, 2004.

6. Informacionnye sistemy i tekhnologii v ehkonomike: uchebnik 2-e izd., dop. i pererab. / pod red. V.I. Lojko [Information systems and technologies in Economics: textbook 2nd ed., EXT. and Rev. / ed. by V. I. Loyko]. M: Finance and statistics, 2003.

7. Kolomiec V. F. Mezhdunarodnye informacionnye sistemy: Uchebnik / pod red. prof. V.P. Gondyul [International information systems: the Textbook / under the editorship of Professor V. P. Gondul]. M: center "Kyiv University», 2001.

8. Litwack J., Lavrov A., Sutherland D. Reforma mezhbyudzhetnyh otnoshenij v Rossii: federalizm sozdannyj rynkom [Reform of inter-budgetary relations in Russia: federalism created by the market]. M: Questions of Economics, 2001. No. 4.

9. Lyubavina S. V. Upravlenie ehkonomicheskimi sistemami: monografiya / avtorskij kollektiv pod red. B. N. Gerasimova [Management of economic systems: monograph / group of authors under editorship of B. N. Gerasimova]. Penza: Privolzhsky House of knowledge, 2017.

10. Minakir P. Transformaciya regional'noj ehkonomicheskoj politiki [Transformation of regional economic policy]. M: Problems of theory and practice of management, 2001. No. 2.

11. North D. Institutions, institutional change and economic performance. M: Foundation of economic book «nachala», 1997.

12. Plunkett L., Hale G. The proactive manager. Translated from English. M: Mir, 1984.

13. Poppel H., Goldstein B. Information technology - the trillion - dollar opportunity. Translated from English. M: Economics, 1990.

14. Smirnova G. N., Sorokin A. A., Telnov Y. F. Proektirovanie ehkonomicheskih informacionnyh sistem: uchebnik / [Design of economic information systems: tutorial]. M: Finance and statistics, 2005.

15. Regionalnaya ehkonomika i upravlenie: ucheb. posobie, 2-e izd., pererab. i dop.[ Regional Economics and management: studies. Handbook, 2nd ed., Rev. and extra]. SPb.: Peter, 2008.

16. Simon H. Theories of decision-making in economics and behavioral science. Translated from English. SPb., 1995.

17. Petrosyants V. Z., Dokholyan S., Petrosyants D. V., Bashirova A. A. Strategiya regionalnogo razvitiya $v$ usloviyah innovacionnyh preobrazovanij ehkonomiki. [Strategy of regional development in the conditions of innovative transformations of economy]. M: Economics, 2011.

18. Strelets I. A. Novaya ehkonomika i informacionnye tekhnologii. [New economy and information technologies]. M.: Examen, 2003.

19. Teoriya sistem i sistemnyj analiz v upravlenii organizaciyami: ucheb. posobie / pod red. V. N. Volkova [Systems theory and system analysis in management: textbook]. M: Finance and statistics, 2006.

20. Schenk R. Conceptual information processing. Translated from English. M: Energy, 1980.

21. Eddowes M., Stansfield R. Decision making Methods. Translated from English. M.: Banks and stock exchanges, 2001.

22. Castells M. The Information Age: Economy, Society and Culture: The Rise of the Network Society. Maiden (Ma.). Oxford: Blackwell Publ., 1996.

23. Stigler $G$. The Economics of information, 1961.

24. Ross A. Industries of the future. AST Publishers, 2017.

25. [An electronic resource]. Access mode: https://minec.astrobl.ru/document/strategia-socialnoekonomiceskogo-razvitia-astrahanskoi-oblasti-do-2020-goda, free. Heading from the screen. 